waste in coal mining" and as the whole subject of the conservation of all our resources developed and was studied, it has always been the engtineers of the country, qualified by training, expert knowledge, and intelligence, who have led and must now lead in the study and broad consideration of our best national policy in conservation. It is the duty of engineers to keep in the forefront of the study and teaching of this matter, and to do their expert share towards shaping the policy of the nation to a course based on reason, economic principles and technical knowledge, rather than on sentimental or political diatribe. A greater danger is threatened to the public interests by the untrained, spasmodic, semi-political, and careless presentation and handling of these matters before the pulblic, by men on whom their importance has suddenly dawned, than by a continuance of erroneous methods of the past. The trouble with most of the plans for railroad and business regulation, and for mineral and water-power conservation, proposed by men untrained and inexperienced in engineering and in business and financial methods and problems, is that their plans are apt to be ideal rather than real, their dicta negative and destructive rather than affirmative, positive and constructive, and their remedies untried and theoretical experiments, rather than of practical and efficient effect.

We should recognize, and this great war's awakening and upturn of all preconceived and preexisting conditions has emphasized, the importance of business-like rather than political management of our national transportation and industrial interests, and of all other national affairs involving expert scientific or business knowledge and training. Our country owes an incalculable debt of gratitude and appreciation to the great interests that have led in and made possible the wonderful transportation and industrial development of our land, and we may find that on a large scale we will be killing the goose that lays the golden egg of national prosperity, if we suffer our railroads and our great industries to be nagged and oppressed to the point of possible insolvency by blind unreasoning prejudice largely born of ignorance, and largely based on political considerations that should not control. The present agitation of the whole subject has a high educational value for our people, and we may be certain that we can in the end trust the horse-sense, the intelligence that in the long run is characteristic of our people, not to be finally led away by 'isms or wild theories, but to use in the final determination of these questions that independence of judgment and sound common sense so characteristic of and inherent in the American people, and for which our politicians so often make the mistake of not giving the people credit.

What better summary of the existing conditions following the war has or can be given than the following from the St. Louis Star, comprehensive in its scope, yet wonderfully succinct in its statement?

A GREATER HUMANITY RISES FROM WAR

During the process of readjustment we shall profit from the lessons the war has taught. In that, aside from freedom for all the peoples of the world, will lie the greatest achievement of the war. When the balance is struck the profit will outweigh the loss. The human lives sacrificed will yield a better and a greater humanity. The cost in dollars will be absorbed quickly in passing years. The material gains will live and produce.

We, in America, have learned something of our strength. We have learned the possibilities of our united effort. We have' learned economy. We have learned concentration. These things will mold themselves into our national character. We shall act with a new inspiration. We shall feel a new confidence. We shall have a new consciousness of the invincibleness of righteous purpose. Henry Sturais DrInker

LEHIGH UNIVERSITY

\section{CHEMISTRY AND MEDICINE: A TRIB. UTE TO THE MEMORY OF JOHN HARPER LONG1}

Dr. LoNG's life and work, so ably portrayed by Professor Dains, are an eminent instance of

1 An address given November 22, 1918, before a joint meeting of the Institute of Medicine of Chicago and the Chicago Section of the American Chemical Society. 
the value of the work which lies in the great field of effort resulting from the relations of chemistry to medicine. For many years the main subjects of his investigations were enzymic action and problems of nutrition, researches of equal interest and importance to the progress of medicine and to the advancement of chemical knowledge. No less close and vital were these relations in the important spheres of influence which Dr. Long had created about himself outside of his laboratory, as instanced by his service of twenty years on the Illinois State Board of Health and by his connection with the Council of Pharmacy and Chemistry of the American Medical Association from its inception in 1905 to the end of his life. The same breadth of interest, supported by his great. ability and fearless honesty, led to his selection as a member of Dr. Remsen's famous referee board, and in the last year of his life also to his election to the presidency of the Institute of Medicine of Chicago, which was founded in large measure to further the cause of medicine through the stimulation of research in all fields contributing to the advancement of medical knowledge.

Dr. Dains has discussed in an admirable fashion the details of Professor Long's valuable contributions to science and to the cause of humanity, and I have felt that I could pay no truer tribute to the high aims and achievements of my life-long colleague and friend than by attempting to outline to-night some of the important features of the relations between chemistry and medicine and thus help to have the cause "carried on" which Dr. Long so nobly served and had so greatly at heart.

From its earliest beginnings chemistry has found in medicine one of its greatest sources of inspiration-indeed, the very name of our science refers to the dawn of chemical knowledge in the temples of Egypt, the "land of Chêmi," where priests prepared simple remedies and studied their chemical nature. This close connection persisted through the centuries and found perhaps its crowning culmination in the persons of two modern giants of the medical world-the greater one, Louis Pasteur, the chemist who turning to medicine and using his chemical knowledge and its exact criteria in its service, founded the knowledge of disease through microscopic organisms, the very foundation stone of modern medicine, and the second, Paul Ehrlich, who inaugurated the present most promising era of combatting these dread causes of disease by the development of specific remedies, produced artificially in the chemical laboratory in the form of pure chemical compounds. Between these two extremes, the cause of disease and its cure, chemistry has found such an infinite variety of lines of effort contributing to medical knowledge that I must necessarily limit my subject and I shall do so by confining myself in large measure to those phases of it with which I am personally most familiar. How necessary such a limitation must be is no better shown than by the fact that at the present moment medical science seems to be turning to chemistry more and more as an essential factor in every one of its fundamental branches. That chemistry was essential in bio-chemistry and in physiology has long been well understood, but of recent years pathology also has turned to chemistry for the solution of its most important problems; the best preparation for a bacteriologist, I am told, is long and advanced training in chemistry; and even the great science of zoology, so long held in thrall by the obvious fact of form, has now turned to chemistry. How vital these applications of our science are, has been impressed most insistently perhaps on me by the the fact that some biologists seem at length to have reached the conclusion that those most important of all factors in human life, in the very evolution of our race, the factors included in the collective name of heredity, must owe their wonderful power of transmission of characters and character in final instance to the chemical nature, the specific chemical character, of chemical molecules.

With this glimpse into the vast vistas of present and future developments in the domain of the relations of chemistry to medicine, I must turn from these most alluring questions 
and ask what my own chosen field of chemistry, which for the lack of a better name we still call pure chemistry, can contribute to the cause of medicine. Let me say at once that I speak almost on the defensive, I have been asked so often by eminent physicians; by physiologists and biologists of every kind, why chemistry is so intolerably slow and backward in solving what are quite obviously chemical problems-problems striking at the very root of our health and happiness. The answer very simply is this: Pure chemistry aims to be and is an exact science; indefinite mixtures of substances, such as our tissues and secretions represent, interest us, it is true, most deeply, but we can handle them altogether successfully only to the extent that we can isolate from them pure principles for exhaustive, complete investigation, so complete that we do not rest until we have dissected the molecule of the pure compound, have put it together again, and thus have acquired first hand knowledge of the exact function of each of its members. In the same way, systems that contain more variables than we can control rigorously, as rigorously as the mathematicians, the physicists and astronomers control their material, pure chemistry puts aside until such a time when our knowledge has advanced far enough to give us exact knowledge of each component in the system, to make possible a rigorous analysis of the whole system. Every physician knows what medicine would be without dissection, without an exact knowledge of the structure and location of the organs and members of the body-every physician knows too how the functioning of the parts in the whole can be understood only by an accurate study first of the functioning of each organ and each member. Now, the scientific dissection and reconstruction of the molecules of important isolated principles is as a rule an extraordinarily difficult problem. Thus it took Baeyer, perhaps the greatest organic chemist of his generation, some fourteen years to determine what we call the structure of indigo, containing only some thirty atoms. But, his success opened the way with the inevitableness of fate to one of man's triumphs over nature: for with the knowledge of its structure, the key was gained for the successful synthesis of indigo and its artificial preparation on a large scale, releasing many acres of land for the growth of other important products for human use. It took altogether some thirty-four years to complete the campaign for the successful production of indigo, and at that the campaign was planned and conducted by some of the keenest minds in our science and sustained by the prospects of rich rewards in gold for the successful issue! Similar vital work was carried out with other important dyes, such as alizarin or turkey red, methylene blue, magenta. I am emphasizing these facts, not only to illustrate the method of pure chemistry, but primarily to show what the successful issue of its efforts means. These and other dyes had been used commercially with an empirical knowledge during the many years that great investigators studied them from the point of view of chemistry as an exact science -but with the successful issue of their efforts in the profound analysis of the molecular structure of fundamental dyes, chemistry has gained for man supreme and practically unlimited power over the whole problem of color! It has made it possible for us to make at will a dye of any properties we may desirefast dyes for any fabric, unstable, sensitive dyes for photography, dyes of any conceivable shade, fluorescing, if you please, with any desired hue! This instance of the power gained by chemistry has already proved to be of great value in medicine, by the development of stains to differentiate cells, microorganisms, tissues of every variety.

The lesson of this conquest of the world of color by man would be wholly lost, if you did not carry from here the conviction that the methods which have scored so brilliant a success in one field are absolutely certain to be equally successful in conquering the greater world of bio-chemistry. The methods evidently are painfully slow. It took two generations to complete the conquest of colorwould ten or twelve generations be too long for the supreme conquest of the chemistry of life? The campaign has already long been 
started and many a great victory is a promise of the complete triumph that must ultimately come. I shall attempt to outline for you three of the greatest problems which chemistry is facing in a titanic effort to invade and explore to its minutest parts nature's most precious domain-life: the problem of the synthetic remedy, the problem of the specific remedy, and greatest of all, the problem of living matter.

A brief survey of the development of our power to produce and control local anesthesia may serve to illustrate the kind of service chemistry is trying to render medicine in the domain of the synthetic remedy. The discovery of the effect of cocaine in removing by a simple local application all sense of pain where it has been applied, is, I believe, considered one of the great blessings of modern medicine, an aid to the surgeon, no less than a godsend to the patient. When cocaine was first exploited, there were two serious drawbacks to its use; one, its great cost-it was said to be worth its weight in gold-which necessarily limited its employment; the other, its poisonous character, by reason of which there were occasional fatalities connected with its employment. The story of the exploration of the structure of the molecule of cocaine, like that of indigo, is for the chemist a most thrilling and romantic tale-great chemists made advances, only to meet with ultimate defeat-exactly as great explorers did in the investment of the secrets of the domain of the North Pole or of the heart of Africa-until finally the penetrating genius of Richard Willstaetter succeeded in reaching the great goal. The results of these investigations are found not only in the fact that medicine has now a host of valuable substitutes for cocaine, which have powerful anesthetic properties without dangerous secondary effects but even more than the gain in materia medica is this: in the conquest of the world of color it was found that color is primarily due to certain specific groups of atoms in the molecules of dyes, or rather, vice versa, that specific combinations of a few atoms in the molecules of compounds give specific properties and functions to these compounds. This is, of course, really a fundamental law of chemistry revealed again in so complex a field as dyes. Now, exactly the same kind of specificity should be found in medicaments-that is, each specific function should be found to be the result of the presence of perfectly specific groups of atoms in the molecules of the medicaments. It is this application of the principles of pure chemistry which we can follow in the planned production of new and better local anesthetics and it is this application which points the way to one of the greatest lines of research for chemistry in the service of medicine-to determine by exhaustive investigation the peculiarities of an atomic group which will give the clean physiological effects which every physician would like to have at hand in the treatment of disease. The path would thus be eventually opened to a truly scientific materia medica. In the dyes we have been able to control secondary effects, such as stability or fluorescence, and we have every reason to believe that chemistry can accomplish the same results and avoid untoward secondary effects in the problem of obtaining specific physiological effects.

The tremendous development of the production of so-called synthetic remedies is the visible manifestation of the application of chemistry to the kind of research I have outlined. A large part of this manufacture of synthetic drugs is, no doubt, of no permanent value, a far too large a portion is unquestionably even detrimental to the best interests of medicine as the result of claims that are, to say the least, too sanguine and often without an adequate basis of fact. Again the lure of gold is marring while stimulating this great effort in behalf of mankind. But that real progress has been made has been ampiy demonstrated by the situation in this country in the matter of synthetic drugs, resulting from our war with Germany: this has separated the wheat from the chaff and shown that there indeed are a number of drugs, invented by chemistry, which may be considered vital in the treatment of disease.

The second line of research in the application of these methods of chemistry to the prob- 
lems of medicine, which should be emphasized, is that which has found its most convincing expression in Ehrlich's great work on salvarsan and neo-salvarsan, now known to us by their American official names as arsphenamine and neo-arsphenamine. This is the most convincing instance of the wonderful opportunities in developing the specific agent that will kill a specific invading germ without permanent injury to its host. Quinine was, I believe, the first specific of this kind, and it would seem that it would have been only a single self-understood step from the use of a natural chemical compound to the development of synthetic chemicals for similar purposes-but it took an Ehrlich to take the first great and successful step in that direction. Ehrlich, like Pasteur, was a chemist before he became interested in medicine and it is important to know that in developing arsphenamine he used all the resources of pure organic chemistry, his special field, changing the structure of the molecule he was developing, here a little, there a little, putting an apparently slight but essential finishing touch here and there, just as a sculptor would handle his clay and his marble. Finally after six hundred and five preliminary studies the product needed to produce the desired effect was perfected! In arsphenamine the ordinary path of synthesis was abandoned, that is, the ordinary path of taking a natural product like indigo, cocaine, or atropine and finding out the secret of the constellation nature had constructed. Ehrlich struck out to build his own cunning molecular contrivance to kill the invading germ without harm to the host and he succeeded brilliantly! For many other diseases due to bacterial invasion medicine is now using specific antitoxins and vaccines, manufactured in some host or medium by the germs themselves. With the curative agency we find inevitably substances poured into our systems which are not needed for the effect desired. and which may indeed be harmful. For instance, a child unfortunate enough to have received a prophylactic dose of diphtheria antitoxin is exposed to the dangers of anaphylactic shock if later an actual attack of diphtheria develops and the treatment with antitoxin is indicated in an effort to save its life. Surely, physicians would prefer to use some pure specific if chemistry could prepare one, equally efficient, equally potent. The effort to prepare such chemical specifics has been blazed by the discovery of arsphenamine and invites untiring research efforts on the part of chemists. Some of the other synthetic drugs which have already been prepared are specifics, if not in the sense of completely curative agents, at least as alleviating remedies of the highest value. The demands for luminal for the relief of epileptics, which have come in since its importation was stopped by the war have been pathetic in the extreme, and the gouty sufferer on the other hand has been grateful that almost without any delay American chemists were able to produce phenyl cinchoninic acid or atophan, which clears the system of the ache-producing uric acid!

We now come to the third and last field of effort of pure chemical research in the service of medicine which I should like to include in this short sketch-the study of the chemistry of life itself, of protoplasmic agencies and activities. Such a study is clearly so fundamental that it must ultimately give the world the rational basis both for preventive and for curative medicine. The problem obviously is a tremendous one that must be attacked by many workers from many sides and it will take generations of toilers to complete the great undertaking. That complete knowledge will come no one can doubt who has followed the brilliant advances made in the last sixty years. At this time I can refer only to a very few phases of this slow but triumphant march of our science to the knowledge of the chemistry of life-a few phases which illustrate different lines of attack' and which at the present moment hold out the greatest promise of success.

Finst, let me recall the fact that Pasteur's first great contribution to science, as a young chemist of twenty-six, was the discovery in a study of the crystalline character of tartaric acid, that matter may be arranged in molecules in space in an unsymmetric fashion, yielding 
distinct forms, which have in the simplest cases the same relations to each other as my right hand bears to my left, and that shortly after, he made the remarkable discovery that living matter discriminates sharply between two such forms, which are identical in every particular except that the one is the optical image of the other. Thus, he found that dextro-tartaric acid is destroyed by ferments, lævo-tartaric acid is not. It is of interest to mention, in passing, that this very discovery, arising out of pure chemical researches, was the fortunate incident in Pasteur's life that drew his attention to fermentation and opened the path to his great work on the germ theory of disease, to which medicine owes its present strength.

The mode of attack used by pure chemistry is to isolate pure compounds and study them exhaustively, both as to structure and as to their chemical activities. In attacking the problem of protoplasm we must isolate such of its components as we can, the materials it uses as food, the materials it excretes, and study each exhaustively. Thus, another great leader in this field, Emil Fischer, has laid the foundation of the chemistry of carbohydrates by his brilliant studies of the monosaccharides. How important these studies are for the science of protoplasmic activity is shown by the fact that of the sixteen stereoisomeric aldehyde-hexoses, differing only in the space arrangements of the atoms in their molecules, only three, d-glucose, d-mannose, d-galactose, are directly fermentable! Fischer, again, in his classical researches on the amino-acids and the polypeptids has been laying another broad and sure foundation for the study of the ultimate chemistry of the proteins. It is characteristic of the greatness and thoroughnessand the slowness-of the methods of pure chemistry that this study of the chemistry of proteins is growing in the same way that a magnificent monument would be erected. It is well-known that any one of the beautiful cathedrals of Europe was constructed as a rule not in one generation and by one architect, but rather slowly grew as the product of the efforts of succeeding generations, of the genius of successive architects. We see now only the foundations of the monument of the chemistry of the proteins, laid with painstaking accuracy, by workers in all countries. None of us will live to see the completion of the monument in all of its glory, but those who best understand the work have a supreme faith in the ultimate realization of their vision-and with it must come an insight into the nature of protoplasm and of life which no other study can hold out to us in like measure.

What a wealth of problems lies ready for the bold investigator! We may think of the isolation and exhaustive study of the active principles of the secretions of the internal glands, on whose presence in balanced proportions our healthy existence depends in so large a measure. Suprarenin or adrenalin has already been isolated by our American Abel and prepared artificially by the Germans, Stolz and Flaecher. The active principle of the thyroid gland has been isolated by E. C. Kendall of the Mayo Laboratories and found so potent, that an unbelievably minute amount injected into patients makes the difference between disease and health. Dr. McCollum is closing in on the secret of the active principles in our food commonly called the vitamins: should they prove to be organic and not vital mineral components, a study of their chemical nature and the structure of their molecules would follow, and what a triumph for humanity if we could then produce them from waste products like coal-tar and help out the fast decreasing ratio between supply and demand of dairy and similar products in crowded populations! You men of medicine do use organs of animals, ground or extracted, to make good a deficiency in this or that secretion in disease, but how much greater would your confidence in your therapy be if in place of mixtures of uncertain potency, pure chemical products were at your disposal. It is not so long since you used to employ your most important specific alkaloids in the same uncertain way, but what modern doctor would now hesitate in his choice between strychnine and nux vomica, atropin and belladonna, morphine and opium! Moreover, the isolation of 
the pure alkaloids by the chemist has put into your hands the swift weapon of intravenous injection and the same promise is held out for the pure isolated principles of glands.

Isolating and investigating pure principles of food, of excretion, of physiological secretion, even to the point of the structure of their molecules, is a great and important task of pure chemistry, but it deals with only half of the great problem. Life is dynamic, it is material in action, and hence there is another great side to the problem of the chemistry of life, namely, the relations of the laws of chemical action to life. Every advance in our studies in physical chemistry, the branch of chemistry in which we study chemical dynamics, has found its important reflection, often its immediate reflection in its applications to life phenomena. Thus, the principle of the conservation of energy in chemical changes forms the basis of a large and vital part of the work on food values and their relation to proper sustenance. Then, we have the applications of the laws of solutions and of the theory of ionization in the use of saline injections, in the problems of fertilization as studied by Loeb, in the study of the regulation of the heart beat. We have the application of the laws of reversibility and equilibrium by Hill and by Emmerling to demonstrate the reversibility of enzymic action and thus to account in some measure for the synthetic processes of protoplasm, without which life would be impossible. The studies of the laws of catalysis or acceleration of action is another study fundamental for the understanding of life, for, as Ostwald has said, our bodies are wonderfully controlled machines in respect to that fundamental factor of nature, the time factor. I need not emphasize the significance of the time factor in medicine, for we all know that health and disease are distinguished in no way more characteristically than by such time factors as heart-beat, respiration, rate of growth, rate of elimination, of decay. Our time controlling devices are essentially the catalyzing enzymes and the investigations of their mode of action, of their production and control in the body belong to the most important ones in medicine. Such diseases of nutrition as gout and diabetes are most likely the result of abnormalities of enzyme supply.

How rapidly a discovery in physical chemistry may find its application in the study of life activities is well illustrated by this instance: Professor Wilder D. Bancroft at Cornell University a few years ago made some extremely interesting observations connecting emulsions of oil in an aqueous medium with the presence of sodium and ealcium oleates in the medium of the emulsion. By varying the ratios he could produce at will an emulsion of oil in the aqueous liquid or an emulsion of the water fluid in the oil. These genial observations were hardly published when Dr. Clowes, of Buffalo, applied their principles successfully to such problems as the clotting of blood, the coagulation of milk, the chemical fertilization of eggs, à la Loeb, and to anesthesia! This work is a brilliant instance of the rôle played by colloid chemistry, the chemistry of colloid dispersions, in life phenomena. Since the major part of our bodies is a complex aggregation of colloid systems and since every particle of protoplasm is itself a colloid, the importance of this side of chemistry for the study of life can not be overestimated.

It is evident, therefore, that all phases of physical chemistry as well as the analytical and synthetical sides of pure chemistry are finding vast fields of investigation for chemists in the domain of medicine and its fundamental sciences, fields drawing to themselves ever increasing numbers of ardent workers. The friend and collaborator whose memory we are cherishing to-night was himself an indefatigable worker in this great cause, whose ultimate goal is a complete and masterful knowledge of the science of living matter. We can in no way pay greater tribute to his memory and devoted career than to pledge ourselves anew to continue our own modest efforts toward the upbuilding of this monumental undertaking of man's courage and genius, although we well know that only fu- 
ture generations will see the glories of the completed monument!

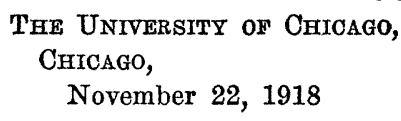

\section{EDUCATIONAL EVENTS}

BIOLOGICAL SURVEYS OF STATES BY THE UNITED STATES DEPARTMENT OF AGRICULTURE

Natural history surveys, dealing with the geographical distribution, habits and relations to environment of birds and mammals, with particular reference to the utility of the information gathered to the proper solution of problems in game protection, public health, forestry, grazing and agricultural practise, were carried forward in several states by the United States Biological Survey, Department of Agriculture, and cooperating institutions during the field season of 1918 .

In Wisconsin the work of the Biological Survey was conducted, as since the beginning of investigations in that state, with the cooperation of the Wisconsin Geological and Natural History Survey, of which Dr. E. A. Birge is director. The personnel of the field party operating during the season included Dr. Hartley H. T. Jackson, Biological Survey, in personal charge; Mr. A. J. Poole, U. S. National Museum, as his temporary assistant, for the Wisconsin Survey, and Mr. A. I. Ortenburger, temporary assistant Professor George Wagner, of the University of Wisconsin, administers the interests of the Wisconsin Survey in the undertaking. Investigations were made in the distribution and habits of mammals, birds, reptiles and amphibians, the greater portion of the season being devoted to the upper Wisconsin River valley.

In central Montana Mr. M. A. Hanna, temporary field assistant, prosecuted the work under the direction of Mr. Edward A. Preble. This is the third consecutive season of field work in Montana, during which the southern half of the state east of the mountains has been covered.

A biological survey of Florida was under- taken by Mr. Arthur H. Howell, with Mr. Charles H. M. Barrett as field assistant for a part of the time. Investigations were made chiefly in the southern part of the state from Lake Okeechobee to Cape Sable and on the west coast from Sarasota Bay northward to Homosassa. Special attention was given to the fauna of the Royal Palm State Park, in the southern Everglades near Homestead.

Field investigations in Arizona in general charge of Mr. E. A. Goldman, now in France as a major in the Sanitary Corps, have been conducted over several seasons, being carried forward during the past summer in extreme southwestern Arizona by $\mathrm{Mr}$. A. Brazier Howell, of California. There is left still unworked the southeastern portion only of the state.

Surveys of New Mexico, North Dakota and Oregon have recently been completed under the general direction of Mr. Vernon Bailey. Reports on the mammals, birds and life zones of these states are completed or in various stages of preparation.

Work in Washington was performed in informal cooperation with the State College of Washington, Pullman, and the State Normal School, Cheney. The personnel of the field parties operating included: Biological Survey, Dr. Walter P. Taylor, in charge, assisted by Mr. George G. Cantwell, reservation inspector, and for a short time by Mr. Stanley G. Jewett, predatory animal inspector; State College of Washington, Professor William T. Shaw, in charge, assisted by Mr. O. H. Homme, temporary field assistant; State Normal School, Cheney, Professor J. W. Hungate. During the two consecutive seasons involved investigations have been carried forward in the southern Cascades, along the Columbia River, in a broad belt across the state from Spokane to Puget Sound, and in southwestern Washington. Mr. Cantwell is continuing the work through the fall and winter months.

\section{THE CENSUS BUREAU}

According to the annual report of Director Rogers, of the Bureau of the Census, the 